\title{
Be seeded or not be seeded? A study with Olympic judo athletes
}

\author{
Leandro Marques Guilheiro', Emerson Franchini2,** \\ 'Universidade do Sul de Santa Catarina, Tubarão, Brazil \\ ${ }^{2}$ Martial Arts and Combat Sports Research Group, School of Physical Education and Sport, University of São Paulo, São Paulo, Brazil
}

The main purpose of the present study was to calculate the probability-based on a Bayesian approach - to win a medal in the Olympic Games given the athlete is seeded and to verify if the number one ranked athlete has any advantage compared to other seeded athletes concerning his/her chances to be Olympic champion. For this, data from athletes who took part in the London 2012 and Rio 2016 Olympic Games were considered. For males the probability of seeded athletes to win a medal was $41.1 \%$ and $42.9 \%$, while for females it was $35.7 \%$ and $44.6 \%$ at London 2012 and Rio 2016, respectively. Furthermore, the probability of athletes ranked as number one to become Olympic cham- pion among the seeded athletes was $19.5 \%$ and $36.8 \%$ for males and $32.3 \%$ and $36.8 \%$ for females in London 2012 and Rio 2016, respectively. Based on these results the cost-benefit of investing human and financial resources to qualify an athletes among the top eight competitors and his/her exposure to competitions - resulting in technical-tactical analysis of the opponent and higher risk of injury — should be carefully analyzed when determining the competition calendar to each athlete.

Keywords: Sports, Bayesian approach, Martial arts

\section{INTRODUCTION}

Since 2009 the International Judo Federation (IJF) established a world ranking list based on different competitions' levels. Before the last Olympic Games the athletes received a specific number of points according to their performance in the following competition: Continental Open, 100 points; Grand Prix, 300 points; Continental Championships, 400 points; Grand Slam, 500 points; World Masters, 700 points; World Championship, 900 points; Olympic Games, 1,000 points. The champion received 100\% of these points, while the silver and bronze medalists received $60 \%$ and $40 \%$ of these points, respectively. Other positions in the competition also resulted in points to the athletes. As the ranking is dynamic across the season, points scored in the last 12 months are $100 \%$ valid, while points obtained in the 13-24 months before a given date are reduced to $50 \%$. Additionally, nowadays the best five results in the 24 months range plus the performance either in the Continental Championship or in the World Masters are con- sidered. According to the ranking position, the first eight athletes taking part in a specific competition are seeded in the draw. Furthermore, the 22 and 14 best ranked male and female athletes area directly classified to the Olympic Games, respectively (International Judo Federation, 2016).

The Olympic Games are the most relevant competition for judo athletes (Franchini and Takito, 2014) and the most traditional nations in this sport need to invest a considerable amount of money to maintain their athletes taking part in the main competitions of the Judo World Tour (Franchini et al., 2016). Although the ranking system has been criticized due to the home advantage effect noticed in these competitions (Ferreira Julio et al., 2013; Krumer, 2017) and to its low predictive value for the Olympic Games performance (Franchini and Julio, 2015), the fact that the draws are seeded has a strong influence on some countries trying to have a larger number of athletes among the top eight in each weight category. However, little is known concerning the real influence of being seeded on final performance in the Olym-
${ }^{*}$ Corresponding author: Emerson Franchini (iD http://orcid.org/0000-0002-0769-8398 School of Physical Education and Sport, University of São Paulo (USP), Av. Prof. Mello Morais, 65, Butantã, São Paulo, SP 05508-030, Brazil Tel: +55-11-3091-2124, Fax: +55-11-3091-3135, E-mail: efranchini@usp.br Received: January 19, 2017 / Accepted: March 9, 2017
This is an Open Access article distributed under the terms of the Creative Commons Attribution Non-Commercial License (http://creativecommons.org/licenses/by-nc/4.0/) which permits unrestricted non-commercial use, distribution, and reproduction in any medium, provided the original work is properly cited. 
pic Games. This information can be valuable to create strategies to optimize athletes' participation in the Judo World Tour competitions and performance in the main judo competition (i.e., Olympic Games), while avoiding the risk of injury (Kim et al., 2015). Additionally, while the first ranked athlete is positioned in the theoretically easier pool, being the number one directs much attention from the opponents as the athlete in such position is normally considered the athlete to be defeated. Thus, the main goal of the present study was to calculate the probability—based on a Bayesian approach — to win a medal in the Olympic Games given the athlete is seeded and to verify if the number one ranked athlete has any advantage compared to other seeded athletes concerning his/her chances to be Olympic champion.

\section{MATERIALS AND METHODS}

\section{Sample}

Data from athletes who took part in the London 2012 and Rio 2016 Olympic Games were considered in the present study, totaling 470 male and 307 female judo athletes from seven weight categories for each sex. In these competitions 112 athletes were seeded (eight for each weight category in each sex) and 56 medals were distributed.

\section{Variables considered}

The main outcome was the probability of getting an Olympic medal given the athlete was seeded (i.e., top eight in the world ranking list) compared to nonseeded athletes, as well as the probability of being Olympic champion given the athlete was the best ranked compared to the other seeded athletes. Thus, the seeded athletes and medal winners were identified in each specific draw during the two Olympic Games editions where this system was applied (i.e., London 2012 and Rio 2016).

\section{Bayesian approach}

If the initial probability $P(M)$ of an event $M$ occurring is influenced by a second given event $C$ to happen, then it is possible to calculate an a posteriori probability $P(M \mid C)$ called conditional probability. Bayesian approach uses the notion of conditional probabilities, but also updates the initial odds with new hypothesis. These new hypothesis work as weights on a weighted average. In short, Bayes' Theorem is stated by:

$$
P\left(M_{i} \mid C\right)=\frac{P\left(M_{i}\right) * P\left(C \mid M_{i}\right)}{\sum_{j=1}^{n} P\left(M_{i}\right) * P\left(C \mid M_{i}\right)}
$$

for all $i=1,2, \ldots, n$.

(Adapted formula from Bussab and Morettin, 2010).

The first step done by the present study was to calculate the probability $P\left(M_{1} \mid C\right)$ of getting an Olympic medal given the athlete was seeded (i.e., top eight in the world ranking list) compared to nonseeded. The following probabilities were used to calculate $P\left(M_{1} \mid C\right)$ :

a) $P\left(M_{1}\right)$ : initial probability of an athlete, seeded or nonseeded, winning a medal is equal to $\frac{R}{N}$, where $R=$ number of medals at stake; $N=$ number of competitors;

b) $P\left(M_{1}^{c}\right)$ : probability of an athlete, seeded or nonseeded, not winning a medal is equal to $1-P\left(M_{1}\right)$;

c) $\mathrm{P}\left(C \mid M_{1}\right)$ : probability of being a seeded athlete given this athlete won a medal is equal to $\frac{W}{R}$, where $W=$ number of seeded athletes who won a medal;

d) $P\left(C \mid M_{1}^{c}\right)$ : probability of being a seeded athlete given this athlete did not win a medal is equal to $\frac{L}{R}$, where $L=$ number of seeded athletes who did not win a medal.

Table 1 presents data and probabilities in London 2012.

Table 2 presents data and probabilities in Rio 2016.

Thus, the probability of getting an Olympic medal given the athlete was seeded (i.e., top eight in the world ranking list) compared to non-seeded was calculated by:

$$
P\left(M_{1} \mid C\right)=\frac{P\left(M_{1}\right) * P\left(C \mid M_{1}\right)}{P\left(M_{1}\right) * P\left(C \mid M_{1}\right)+P\left(M_{1}^{C}\right) * P\left(C \mid M_{1}^{C}\right)}
$$

According to the Table 1, for example, the probability of an athlete getting an Olympic medal, in London 2012, given that this athlete was seeded in the under 66-kg weight category is equal to $\frac{0.111 * 0.500}{0.111 * 0.500+0.889 * 0.187} \cong 0.250$.

The second step done by the present study was to calculate the probability $P\left(M_{2} \mid C\right)$ of being Olympic champion given the athlete was the best ranked one compared to the other seeded athletes. In this case, the probabilities were not calculated by categories, but among males and females, as well as in London 2012 and Rio 2016. To finally calculate $P\left(M_{2} \mid C\right)$, the following probabilities were previously found:

(a) $P\left(M_{2}\right)$ : initial probability of the best seeded athlete being Olympic champion is equal to $\frac{O}{S}$, where $O=$ number of Olympic champions; $S=$ number of seeded athletes;

(b) $P\left(M_{1}^{c}\right)$ : probability of the best seeded athlete not being Olympic champion is equal to $1-P\left(M_{2}\right)$;

(c) $P\left(C \mid M_{2}\right)$ : probability of being the best seeded athlete given 
Table 1. Basic data and probabilities for London 2012 Olympic Games

\begin{tabular}{|c|c|c|c|c|c|c|c|c|}
\hline Sex \& age & $\mathrm{R}$ & $N$ & W & $\mathrm{L}$ & $P\left(M_{1}\right)(\%)$ & $P\left(M_{1}^{c}\right)(\%)$ & $\mathrm{P}\left(\mathrm{C} \mid \mathrm{M}_{1}\right)(\%)$ & $P\left(C \mid M_{1}^{c}\right)(\%)$ \\
\hline \multicolumn{9}{|l|}{ Male (kg) } \\
\hline$<60$ & 4 & 37 & 3 & 5 & 10.8 & 89.2 & 75.0 & 15.2 \\
\hline 66 & 4 & 36 & 2 & 6 & 11.1 & 88.9 & 50.0 & 18.8 \\
\hline 73 & 4 & 34 & 4 & 4 & 11.8 & 88.2 & 100.0 & 13.3 \\
\hline 81 & 4 & 34 & 4 & 4 & 11.8 & 88.2 & 100.0 & 13.3 \\
\hline 90 & 4 & 30 & 3 & 5 & 13.3 & 86.7 & 75.0 & 19.2 \\
\hline 100 & 4 & 30 & 4 & 4 & 13.3 & 86.7 & 100.0 & 15.4 \\
\hline$>100$ & 4 & 32 & 3 & 5 & 12.5 & 87.5 & 75.0 & 17.9 \\
\hline \multicolumn{9}{|l|}{ Female (kg) } \\
\hline 48 & 4 & 19 & 4 & 4 & 21.1 & 78.9 & 100.0 & 26.7 \\
\hline 52 & 4 & 23 & 1 & 7 & 17.4 & 82.6 & 25.0 & 36.8 \\
\hline 57 & 4 & 25 & 3 & 5 & 16.0 & 84.0 & 75.0 & 23.8 \\
\hline 63 & 4 & 24 & 4 & 4 & 16.7 & 83.3 & 100.0 & 20.0 \\
\hline 70 & 4 & 22 & 2 & 6 & 18.2 & 81.8 & 50.0 & 33.3 \\
\hline 78 & 4 & 21 & 3 & 5 & 19.0 & 81.0 & 75.0 & 29.4 \\
\hline$>78$ & 4 & 20 & 3 & 5 & 20.0 & 80.0 & 75.0 & 31.3 \\
\hline
\end{tabular}

R, number of medals at stake; N, number of competitors; W, number of seeded athletes who won a medal; L, number of seeded athletes who did not win a medal.

Table 2. Basic data and probabilities for Rio 2016 Olympic Games

\begin{tabular}{|c|c|c|c|c|c|c|c|c|}
\hline Sex \& weight & $\mathrm{R}$ & $N$ & W & $L$ & $\mathrm{P}\left(\mathrm{M}_{1}\right)(\%)$ & $\mathrm{P}\left(\mathrm{M}_{1}^{\complement}\right)(\%)$ & $\mathrm{P}\left(\mathrm{C} \mid \mathrm{M}_{1}\right)(\%)$ & $\mathrm{P}\left(\mathrm{C} \mid \mathrm{M}_{1}^{c}\right)(\%)$ \\
\hline \multicolumn{9}{|l|}{ Male (kg) } \\
\hline$<60$ & 4 & 35 & 4 & 4 & 11.4 & 88.6 & 100.0 & 12.9 \\
\hline 66 & 4 & 34 & 3 & 5 & 11.8 & 88.2 & 75.0 & 16.7 \\
\hline 73 & 4 & 35 & 3 & 5 & 11.4 & 88.6 & 75.0 & 16.1 \\
\hline 81 & 4 & 33 & 3 & 5 & 12.1 & 87.9 & 75.0 & 17.2 \\
\hline 90 & 4 & 35 & 3 & 5 & 11.4 & 88.6 & 75.0 & 16.1 \\
\hline 100 & 4 & 34 & 4 & 4 & 11.8 & 88.2 & 100.0 & 13.3 \\
\hline$>100$ & 4 & 31 & 4 & 4 & 12.9 & 87.1 & 100.0 & 14.8 \\
\hline \multicolumn{9}{|l|}{ Female (kg) } \\
\hline 48 & 4 & 23 & 4 & 4 & 17.4 & 82.6 & 100.0 & 21.1 \\
\hline 52 & 4 & 22 & 4 & 4 & 18.2 & 81.8 & 100.0 & 22.2 \\
\hline 57 & 4 & 23 & 3 & 5 & 17.4 & 82.6 & 75.0 & 26.3 \\
\hline 63 & 4 & 26 & 4 & 4 & 15.4 & 84.6 & 100.0 & 18.2 \\
\hline 70 & 4 & 24 & 2 & 6 & 16.7 & 83.3 & 50.0 & 30.0 \\
\hline 78 & 4 & 18 & 4 & 4 & 22.2 & 77.8 & 100.0 & 28.6 \\
\hline$>78$ & 4 & 17 & 4 & 4 & 23.5 & 76.5 & 100.0 & 30.8 \\
\hline
\end{tabular}

R, number of medals at stake; N, number of competitors; W, number of seeded athletes who won a medal; L, number of seeded athletes who did not win a medal.

this athlete was Olympic champion is equal to $\frac{B}{A}$, where $B=$ number of best seeded athletes who were Olympic champions; $A=$ number of seeded athletes who were Olympic champions;

(d) $P\left(C \mid M_{2}^{C}\right)$ : probability of being the best seeded athlete given this athlete was not Olympic champion is equal to $\frac{D}{E}$, where $D=$ number of best seeded athletes who was not Olympic champions; $E$ = number of seeded athletes who were not
Olympic champions.

Table 3 presents data and probabilities in London 2012 and Rio 2016.

Thus, the probability of being Olympic champion given the athlete was the best ranked compared to the other seeded athletes was calculated by:

$$
P\left(M_{2} \mid C\right)=\frac{P\left(M_{2}\right) * P\left(C \mid M_{2}\right)}{P\left(M_{2}\right) * P\left(C \mid M_{2}\right)+P\left(M_{2}^{C}\right) * P\left(C \mid M_{2}^{C}\right)}
$$


Table 3. Basic data and probabilities for London 2012 and Rio 2016 Olympic Games

\begin{tabular}{lccccc}
\hline \multirow{2}{*}{ Variable } & \multicolumn{2}{c}{ London 2012} & & \multicolumn{2}{c}{ Rio 2016 } \\
\cline { 2 - 3 } \cline { 5 - 6 } & Male & Female & & Males & Females \\
\hline 0 & 7 & 7 & & 7 & 7 \\
$S$ & 56 & 56 & & 56 & 56 \\
$B$ & 1 & 2 & & 2 & 2 \\
$A$ & 4 & 4 & & 3 & 3 \\
$D$ & 6 & 5 & & 5 & 5 \\
$E$ & 45 & 45 & & 46 & 46 \\
$P\left(M_{2}\right)(\%)$ & 12.5 & 12.5 & & 12.5 & 12.5 \\
$P\left(M_{1}^{c}\right)(\%)$ & 87.5 & 87.5 & & 87.5 & 87.5 \\
$P\left(C \mid M_{2}\right)(\%)$ & 20.0 & 33.3 & & 40.0 & 40.0 \\
$P\left(C \mid M_{2}^{c}\right)(\%)$ & 11.8 & 10.0 & & 9.8 & 9.8
\end{tabular}

The variables $0, S, B, A, D$,and $E$ are used to calculate the probabilities used on Bayes Formula.

0 , number of Olympic champions; $S$, number of seeded athletes; $B$, number of best seeded athletes who were Olympic champions; $A$, number of seeded athletes who were Olympic champions; $D$, number of best seeded athletes who was not Olympic champions; $\mathrm{E}$, number of seeded athletes who were not Olympic champions.

According to the Table 3, for example, the probability of an athlete being Olympic Champion given that this athlete was the best male seeded in his category, London 2012, is equal to $\frac{0.125 * 0.200}{0.125 * 0.200+0.875 * 0.118} \cong 0.195$.

\section{Ethical issues}

The draws of each weight category for each sex and Olympic Games edition were retrieved from the IJF website (http://www. ijf.org) and these archive data are from open-access. Morley and Thomas (2005) affirm that there are no ethical issues in analyzing or interpreting these data since they were obtained in secondary form and not generated by experimentation. In addition, athletes' personal identifications were replaced by a code, ensuring anonymity and confidentiality. This process was used in previous studies analyzing competitions of the world ranking list (Ferreira Julio et al., 2013; Franchini and Julio, 2015; Franchini et al., 2016). All procedures were approved by the local research ethic committee (process 105/2010).

\section{RESULTS}

Table 4 presents the probability of seeded athletes to win medals in each Olympic Games.

For males the probability of seeded athletes to win a medal was $41.1 \%$ and $42.9 \%$, while for females it was $35.7 \%$ and $44.6 \%$ at
Table 4. Probability of seeded athletes to win medal at Olympic Games

\begin{tabular}{lcc}
\hline $\begin{array}{c}\text { Sex \& weight } \\
\text { Male }(\mathrm{kg})\end{array}$ & $\begin{array}{c}\text { Probability of seeded } \\
\text { athletes to win a medal at } \\
\text { London 2012 (\%) }\end{array}$ & $\begin{array}{c}\text { Probability of seeded } \\
\text { athletes to win a medal at } \\
\text { Rio 2016 }(\%)\end{array}$ \\
\hline 60 & 37.5 & \\
66 & 25.0 & 50.0 \\
73 & 50.0 & 37.5 \\
81 & 50.0 & 37.5 \\
90 & 37.5 & 37.5 \\
100 & 50.0 & 37.5 \\
$>100$ & 37.5 & 50.0 \\
Female $(\mathrm{kg})$ & & 50.0 \\
48 & 50.0 & \\
52 & 12.5 & 50.0 \\
57 & 37.5 & 50.0 \\
63 & 50.0 & 37.5 \\
70 & 25.0 & 50.0 \\
78 & 37.5 & 25.0 \\
$>78$ & 37.5 & 50.0 \\
\hline
\end{tabular}

London 2012 and Rio 2016, respectively. Additionally, the probability of athletes ranked as number one to become Olympic champion among the seeded athletes was $19.5 \%$ and $36.8 \%$ for males and 32.3\% and 36.8\% for females in London 2012 and Rio 2016, respectively.

\section{DISCUSSION}

The main findings of the present study was that athletes seeded had a chance of $25.0 \%$ to $50.0 \%$ for males and between $12.5 \%$ to $50.0 \%$ for females to win an Olympic medal, resulting in an overall probability of around $41.1 \%$ when all groups are considered. Moreover, being the first seeded athlete (i.e., ranked number one) resulted in an overall probability to become Olympic champion of around $31.0 \%$ when male and female athletes are grouped. Based on this information, it seems relevant to have seeded athletes, but being the top ranked athlete does not seem to result in an expressive advantage to become Olympic champion compared to other seeded athletes.

As the world ranking list is used as the main criteria to qualify to the Olympic Games, which is the most prestigious competition to judo athletes (Franchini and Takito, 2014), and the position in this ranking determines the seeded athletes in each weight category, most athletes take part in four to eight competitions during the year to guarantee their direct qualification to the competition (i.e., top 22 for males and top 14 for females) (Franchini et al., 
2016). The competitions comprising the Judo World Tour are disputed in different countries, although the higher concentration be in Europe (Ferreira Julio et al., 2013). Thus, countries with limited financial resources or with high number of elite judo athletes should consider the specific cost-benefit of conducting such travels specifically to qualify their athletes to the Olympic Games or focusing on the seeded positions. Moreover, the fact that a high number of injuries is observed in high-level judo athletes (Kim et al., 2015), the exposure to a higher number of competition, the interval needed to increase the probability of winning (Franchini et al., 2016), the high physiological demand of judo competitions (Franchini et al., 2013), the fact that many judo athletes lose weight to compete (Artioli et al., 2010)—which also increases the risk of injuries (Green et al., 2007)—and the training needed to prepare athletes to them (Franchini and Takito, 2014; Franchini et al., 2014) can be considered when elaborating the competition calendar to each athlete. These aspects are especially important, as the ranking position is a poor predictor of the final result during the Olympic Games (Franchini and Julio, 2015) and some categories are more balanced than others (Krumer, 2017).

Although the number one ranked athlete is positioned in a theoretically easier pool (as the best ranked athlete to be confronted in the semifinal is the number four, while number two may confront the number three in a semifinal) the probability of becoming Olympic champion is not so high. This seems to happen due to the large focus that opponents rely on the top ranked athlete and to the common pressure media and supporters put on these athletes.

In summary, the present study used a Bayesian approach to determine the probability of seeded athletes to win a medal in the Olympic Games compared to other athletes and the probability of number one ranked athletes to become Olympic champions compared to seeded athletes. As the probability of seeded athletes to get an Olympic medal is around $41.1 \%$ and the probability of number one ranked athletes to become Olympic champions is $31.0 \%$, the cost-benefit of investing human and financial resources to this goal and the athlete exposure to competitions-resulting in technical-tactical analysis of the opponent and higher risk of injury—should be carefully analyzed when determining the competition calendar to each athlete.

\section{CONFLICT OF INTEREST}

No potential conflict of interest relevant to this article was reported.

\section{ACKNOWLEDGMENTS}

The last author (EF) is supported by $\mathrm{CNPq}(302242 / 2014-7)$.

\section{REFERENCES}

Artioli GG, Gualano B, Franchini E, Scagliusi FB, Takesian M, Fuchs M, Lancha AH Jr. Prevalence, magnitude, and methods of rapid weight loss among judo competitors. Med Sci Sports Exerc 2010;42:436-442.

Bussab WO, Morettin PA. Estatística básica (basic statistics). São Paulo (SP): Saraiva; 2010. p. 557.

Ferreira Julio U, Panissa VL, Miarka B, Takito MY, Franchini E. Home advantage in judo: a study of the world ranking list. J Sports Sci 2013; 31:212-218.

Franchini E, Artioli GG, Brito CJ. Judo combat: time-motion analysis and physiology. Int J Perform Anal Sport 2013;13:624-641.

Franchini E, Brito CJ, Fukuda DH, Artioli GG. The physiology of judo-specific training modalities. J Strength Cond Res 2014;28:14741481.

Franchini E, Julio UF. The judo world ranking list and the performances in the 2012 London Olympics. Asian J Sports Med 2015;6:e24045.

Franchini E, Takito MY. Olympic preparation in Brazilian judo athletes: description and perceived relevance of training practices. J Strength Cond Res 2014;28:1606-1612.

Franchini E, Takito MY, da Silva RM, Shiroma SA, Wicks L, Julio UF. Optimal interval for success in judo world ranking competitions. Int J Sports Physiol Perform 2016 Sep 15 [Epub]. https://doi.org/10.1123/ ijspp.2016-0375.

Green CM, Petrou MJ, Fogarty-Hover ML, Rolf CG. Injuries among judokas during competition. Scand J Med Sci Sports 2007;17:205-210.

International Judo Federation [Internet]. Lausanne (Switzerland): International Judo Federation; c2007-2016 [cited 2016 Dec 17], Available from: http://www.ijf.org.

Kim KS, Park KJ, Lee J, Kang BY. Injuries in national Olympic level judo athletes: an epidemiological study. Br J Sports Med 2015;49:1144-1150.

Krumer A. On winning probabilities, weight categories, and home advantage in professional judo. J Sports Econ 2017;18:77-96.

Morley B, Thomas D. An investigation of home advantage and other factors affecting outcomes in English one-day cricket matches. J Sports Sci 2005;23:261-268. 